Article

\title{
Relations of CYP2C19*2 genetic polymorphisms to plasma and saliva concentrations of diazepam in patients hospitalized for alcohol withdrawal
}

\author{
Valentin Yu. Skryabin ${ }^{1,2 *}$, Mikhail S. Zastrozhin ${ }^{1,2}$, Elena A. Grishina ${ }^{2}$, Kristina A. Ryzhikova², Valery V. Ship- \\ itsyn", Tatiana E. Galaktionova ${ }^{2}$, Evgeny A. Bryun ${ }^{1,2}$, Dmitry A. Sychev ${ }^{2}$
}

\begin{abstract}
Citation: Skryabin, V.Yu.;
Zastrozhin, M.S.; Grishina, E.A.;

Ryzhikova, K.A.; Shipitsyn, V.V.;

Galaktionova, T.E.; Bryun, E.A.;

Sychev, D.A. Relations of

CYP2C19*2 genetic polymorphisms

to plasma and saliva concentrations

of diazepam in patients hospitalized

for alcohol withdrawal. Personalized

Psychiatry and Neurology 2021, 1 (1): 84-92
\end{abstract}

Chief Editor: Nikolay G. Neznanov, D Med Sci, Professor

Received: 22 March 2021

Accepted: 38 March 2021

Published: 10 April 2021

Publisher's Note: V. M. Bekhterev NMRC PN stays neutral with regard to jurisdictional claims in published maps and institutional affiliations.

Copyright: $\odot 2021$ by the authors.

\author{
${ }^{1}$ Moscow Research and Practical Centre on Addictions of the Moscow Department of Healthcare; \\ mnpcn@zdrav.mos.ru \\ 2 Russian Medical Academy of Continuous Professional Education of the Ministry of Health of the Russian \\ Federation; rmapo@rmapo.ru \\ *Correspondence: sardonios@yandex.ru (V.Yu.S.)
}

\begin{abstract}
Diazepam is one of the most widely prescribed tranquilizers for the therapy of alcohol withdrawal syndrome (AWS). However, diazepam therapy often turns out to be ineffective, and some patients experience dose-dependent adverse drug reactions. Previous studies have shown that the metabolism of diazepam involves the CYP2C19 isoenzyme, whose activity is highly dependent on polymorphism of the encoding gene. The objective of our study was to investigate the effects of CYP2C19*2 genetic polymorphisms on plasma and saliva concentrations of diazepam as well as its impact on the efficacy and safety rates of therapy in patients with AWS. The study was conducted on 100 Russian male patients with AWS who received diazepam in injections at a dosage of 30.0 $\mathrm{mg} /$ day for 5 days. Genotyping was performed by real-time polymerase chain reaction. The efficacy and safety assessment was performed using psychometric scales. We revealed differences in the efficacy and safety of therapy in patients with different CYP2C19 681G>A genotypes. Therapeutic drug monitoring (TDM) revealed the statistically significant differences in the levels of diazepam plasma concentration: $(G G) 199.83$ [82.92; 250.58] vs $(G A+A A) 313.47$ [288.99; 468.33], $\mathrm{p}=0.040$, and diazepam saliva concentration: $(G G) 2.80[0.73 ; 3.80]$ vs $(G A+A A) 5.33[5.14 ; 6.00], \mathrm{p}=0.003)$.
\end{abstract}

Keywords: pharmacogenetics; benzodiazepines; diazepam; biotransformation; personalized medicine; CYP2C19; alcohol withdrawal

\section{Introduction}

Today benzodiazepines (BZDs) are among the most widely prescribed medicinal products in the world [1]. They have the largest and the best evidence base in the treatment of alcohol withdrawal syndrome (AWS), and are considered the gold standard [2]. Currently the problem of personalized approach to the prescription of BZDs is poorly developed in the scientific community. The wide use of these medications creates a misleading impression that it does not require the personalized approach. Therefore, despite the high frequency of administration of BZDs, their dose selection is currently empirically based. According to the available scientific data, in a subset of patients, AWS worsens despite escalating doses of BZDs [3]. Such patients represent a severe alcohol withdrawal state and a serious challenge to practitioners due to the acuity and refractoriness of the disorder $[4,5]$. The incidence rates of this state are unknown, but patients suffering from the resistant AWS were found to have a higher rate of intubation, longer ICU stays, and a greater risk of nosocomial infections in comparison with the patients with the AWS who 
response to BZDs [5, 6]. Meanwhile, the use of the exceedingly high doses of BZDs in this cohort of patients may result in the occurrence of adverse drug reactions (ADRs).

Today it is well known that clinical responses to BZDs vary widely between individuals. [1]. The studies of the pharmacogenetics of BZDs usually focus on the genes of cytochrome P450 (CYP) enzymes, which are among the factors that contribute to the pharmacokinetic (PK) variability of drugs. Diazepam is mainly metabolized via CYP2C19 and CYP3A4 to its major active metabolite, desmethyldiazepam. Recent studies revealed the effect of CYP2C19 and CYP3A4 genetic polymorphisms on the pharmacokinetics of BZDs [7-10]. The differences in the activity of these enzymes are genetically determined. Currently there is a lack of data on the pharmacogenetics of BZDs in patients with AWS [11]. It creates conditions for examining this issue.

\section{Objective}

The objective of our study was to investigate the effect of CYP2C19*2 genetic polymorphisms on both plasma and saliva concentration levels of diazepam as well as its impact on the efficacy and safety rates of therapy in patients with AWS.

\section{Materials and Methods}

\section{Clinical characteristics of patients}

The study included 100 male patients (average age $-42.66 \pm 9.8$ years). Inclusion criteria were the diagnosis of "Mental and behavioral disorders due to use of alcohol. Withdrawal state, uncomplicated" (F10.30, according to ICD-10); written informed consent obtained from the patient; an initial phase of AWS (abstinence from alcohol for at least 8 hours, but no longer than 48 hours prior to the inclusion in study); presence of anxiety, fear or emotional tension in the clinical presentation of the patient; Clinical Institute Withdrawal Assessment for Alcohol scale (CIWA-Ar) score more than 10. Exclusion criteria were presence of any other mental disorders or severe somatic disorders (except alcoholic hepatitis and toxic encephalopathy); presence of any other psychotropic medications in treatment regimen except diazepam; creatinine clearance values $<50 \mathrm{~mL} / \mathrm{min}$, creatinine concentration in plasma $\geq 1.5 \mathrm{mg} / \mathrm{dL}$ (133 mmol/L); body weight less than $60 \mathrm{~kg}$ or greater than $100 \mathrm{~kg}$; age of 75 years or more, and presence of any contraindications for diazepam use.

For the therapy of anxiety, fear and emotional tension in the clinical presentation of AWS, patients received diazepam in intramuscular injections at a dose of $30.0 \mathrm{mg}$ per day.

\section{Therapy efficacy and safety evaluation}

To evaluate the diazepam efficacy, an international well-validated psychometric scale was used: Clinical Institute Withdrawal Assessment for Alcohol scale (CIWA-Ar) [12]. The safety profile was evaluated using The UKU Side-Effect Rating Scale (UKU) [13]. Patients were examined on days 1 and 5 of diazepam therapy.

\section{Genotyping}

Venous blood samples collected in vacuum tubes VACUETTE® (Greiner Bio-One, Austria) on the fifth day of diazepam therapy were used for genotyping. The real-time polymerase chain reaction was performed using DNA amplifiers "Dtlite" of DNA Technology (Moscow, Russia), CFX96 Touch Real Time System with CFX Manager software of Bio-Rad Laboratories Inc. (Hercules, CA, USA) and sets "SNP-screen" of "Syntol" (Moscow, Russia). It was used to determine the single nucleotide polymorphisms 
(SNP's) 681G>A of the gene CYP2C19*2 (rs4244285). In every "SNP-screen" set, two allelespecific hybridizations were used, which allowed determining two alleles of studied polymorphism separately on two fluorescence channels.

\section{Therapeutic drug monitoring}

For the therapeutic drug monitoring (TDM), venous blood samples were collected on the day 5 of diazepam therapy. The plasma calibration standards (St) and quality control samples (QC) were made from a stock solution prepared by consistent dissolving of substantial amounts in methanol with subsequent dilution to the relevant concentrations. Calibration curve was created using 5, 10, 20, 50, 100, 200, 500, 1000, $2000 \mathrm{ng} / \mathrm{mL}$ calibration standards along with $5 \mathrm{ng} / \mathrm{mL}$ (LLOQ), $15 \mathrm{ng} / \mathrm{mL}$ (Low QC), $1000 \mathrm{ng} / \mathrm{mL}$ (Medium QC), and $1500 \mathrm{ng} / \mathrm{mL}$ (High QC) quality control samples (QC). Diazepam (250 ng/mL in acetonitrile) was used as the internal standard.

\section{Sample preparation}

Samples were prepared using a protein precipitation method. A $1.5 \mathrm{~mL}$ tube was filled with $200 \mathrm{mcL}$ of analyzed plasma sample and $600 \mathrm{mcL}$ of acetonitrile containing the internal standard. The mixture was shaken on Vortex for 10 minutes, and then samples were centrifuged at $14,500 \mathrm{~g}$ for 10 minutes at $4{ }^{\circ} \mathrm{C}$. Then the supernatant was transferred to an autosampler vial. Samples were analyzed using the HPLC system Agilent 1260 (Agilent Technologies, California, USA) and tandem mass selective detector Agilent 6460 (Agilent Technologies, California, USA) with Jet Stream Electrospray Ionization Source.

\section{Conditions of chromatographic analysis}

Stationary phase: column Agilent Poroshell 120 EC-C18 $(2.7 \mu \mathrm{m}, 3.0 \mathrm{~mm}<\mathrm{U}+00 \mathrm{D} 7>$ $50 \mathrm{~mm}$ ) with the precolumn InfinityLab Poroshell $120 \mathrm{EC}-\mathrm{C} 18(2.7 \mu \mathrm{m}, 3.0 \mathrm{~mm}<\mathrm{U}+00 \mathrm{D} 7>$ $5.0 \mathrm{~mm}$ ) (Agilent Technologies, California, USA). The column temperature was $50^{\circ} \mathrm{C}$. The mobile phase consisted of the A eluent $(10 \mathrm{mM}$ ammonium formate in $0.1 \%$ formic acid) and B eluent (methanol in $0.1 \%$ formic acid). The flow rate was $0.4 \mathrm{~mL} / \mathrm{min}$. The gradient elution process was performed; the gradient of the mobile phase is presented in Table 1.

The analysis time was 9.0 minutes for every sample. The volume of the inserted sample was $2 \mathrm{mcL}$. Retention time under the given conditions was $4.75 \mathrm{~min}$ for diazepam and $4.84 \mathrm{~min}$ for the internal standard.

\section{Conditions of mass-spectrometry determination}

We used positive mode electrospray ionization for mass-selective detection. Detector registered following MRM-transitions: from $349.0 \mathrm{~m} / \mathrm{z}$ [M+H+] to $206.1 \mathrm{~m} / \mathrm{z}$ (collision cell energy $40 \mathrm{~V}$ ) and from $349.0 \mathrm{~m} / \mathrm{z}[\mathrm{M}+\mathrm{H}+]$ to $184.0 \mathrm{~m} / \mathrm{z}$ (collision cell energy $32 \mathrm{~V}$ ) for diazepam; from $285.1 \mathrm{~m} / \mathrm{z}$ [M+H+] to $193.1 \mathrm{~m} / \mathrm{z}$ (collision cell energy $32 \mathrm{~V}$ ) and from $285.1 \mathrm{~m} / \mathrm{z}$ $[\mathrm{M}+\mathrm{H}+]$ to $154.1 \mathrm{~m} / \mathrm{z}$ (collision cell energy $24 \mathrm{~V}$ ) for the internal standard. The voltage on phragmentor for diazepam and internal standard was $156 \mathrm{~V}$ and $166 \mathrm{~V}$, respectively. The voltage on capillary was $3.5 \mathrm{kV}$, the temperature of desiccant gas was $350^{\circ} \mathrm{C}$, nitrogen flow was $6 \mathrm{~L} / \mathrm{min}$. Nebulizers pressure was 45 psi, sheath gas temperature was $375^{\circ} \mathrm{C}$, sheath gas flow was $11 \mathrm{~L} / \mathrm{min}$. 
Table 1. Gradient of the mobile phase.

\begin{tabular}{ccc}
\hline Time, min & Part of eluent $\mathbf{A}, \boldsymbol{\%}$ & Part of eluent $\mathbf{B}, \boldsymbol{\%}$ \\
\hline 0.00 & 95 & 5 \\
0.50 & 95 & 5 \\
1.00 & 50 & 50 \\
1.50 & 5 & 95 \\
3.00 & 5 & 95 \\
3.01 & 95 & 5 \\
5.00 & 95 & 5 \\
\hline
\end{tabular}

\section{Method validation}

The methodology used in the study met FDA Guidance for Industry: Bioanalytical method validation. Calibration dependence was linear for diapason at 0.5-200 ng/mL. Correlation coefficients were normal (at least 0.99). We evaluated the intra- and inter-cycles precision and accuracy rates. Precision and accuracy rates were normal (no more than $20 \%$ at LLOQ, no more than $15 \%$ for other points). The matrix effect had no influence.

\section{Local ethical committee}

The research was approved by the local ethical committee of the Moscow Research and Practical Centre on Addictions of the Moscow Department of Healthcare (The protocol No. 07-17 from 11/28/2017).

\section{Statistical analysis}

Statistical analysis of the results was performed with non-parametric methods using the «Statsoft Statistica v. 10.0» (Dell Statistica, Tulsa, OK, USA). The normality of samples distribution was evaluated using W-Shapiro-Wilk test and taken into account when choosing a method. The differences were considered statistically significant at $p<0.05$ (power in excess of $80 \%$ ). Multiple samples of continuous data were compared using the analysis of variance (ANOVA/MANOVA). To determine the correlation between quantitive characteristics Spearman rank correlation coefficient $(r s)$ was calculated. Research data are presented as the median and interquartile range (Me [Q1; Q3]) or, in case of a normal distribution, as the arithmetic mean and standard deviation (Mean $\pm \mathrm{SD}$ ).

\section{Results}

The CYP2C19 genotyping by polymorphic marker $681 G>A(r s 4244285)$ performed in 100 patients have revealed the following:

- The number of patients with GG genotype accounted for 79 (79\%);

- The number of patients with GA or $A A$ genotype accounted for 21 (21\%).

The distribution of genotypes corresponded to Hardy-Weinberg equilibrium for the European population $\left(\chi^{2}=2.18, p<0.001\right)$.

To investigate the efficacy of therapy in patients with different genotypes, the twoway analysis of variance (ANOVA) was performed including the CYP2C19 genotype and the day of the study as covariates. The results of data analysis performed for the CIWAAr scale in patients with different genotypes are presented in Table 2.

Dynamics of changes in CIWA-Ar scale scores across patients with different genotypes by polymorphic marker $681 G>A(r s 4244285)$ are shown in Figure 1. 
Table 2. CIWA-Ar scale scores in patients with different genotypes from Day 1 to Day 6 of the study.

\begin{tabular}{ccccccc}
\hline \multirow{2}{*}{ Genotypes } & \multicolumn{7}{c}{ CIWA-Ar scale scores } \\
& \multicolumn{7}{c}{ Day 1} & Day 2 & Day 3 & Day 4 & Day 5 & Day 6 \\
\cline { 2 - 6 } & $21[18 ; 24]$ & $14[12 ; 16]$ & $14[11 ; 16]$ & $13[10 ; 14.75]$ & $12[10 ; 14]$ & $13[10 ; 15]$ \\
GG & $24[22 ; 26]$ & $19[16 ; 22]$ & $17[14 ; 19]$ & $14[11 ; 16]$ & $12[9 ; 14]$ & $12[9 ; 14]$ \\
\hline
\end{tabular}

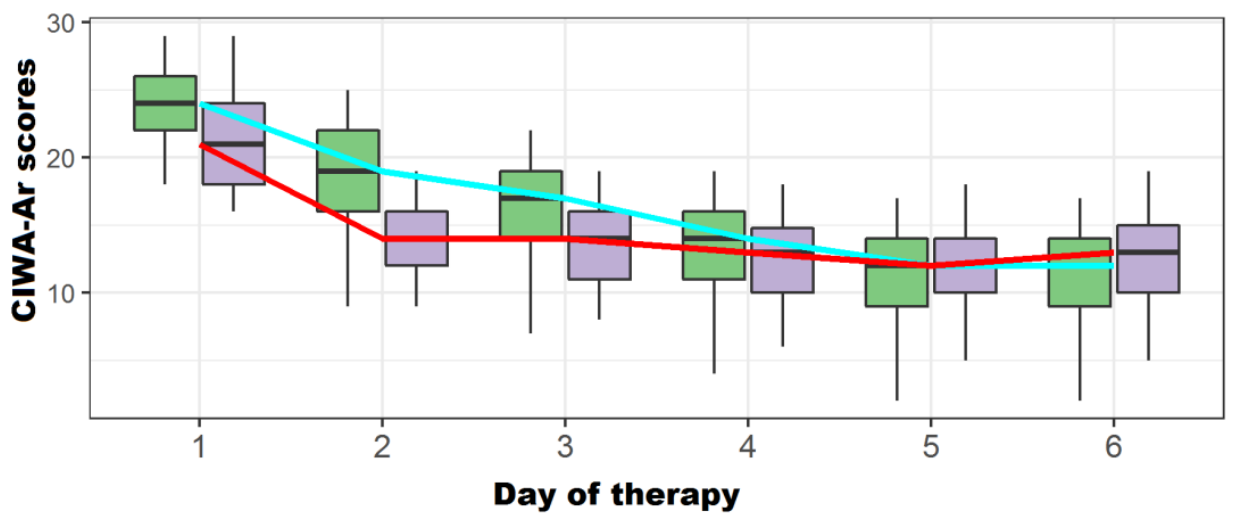

GA+AA 官 GG

Figure 1. Dynamics of changes in CIWA-Ar scale scores across patients with different genotypes from Day 1 to Day 6 of therapy.

Table 3. Comparison of CIWA-Ar scale scores in patients with different genotypes from Day 1 to Day 6 of the study.

\begin{tabular}{ccc}
\hline Variables & F & p-value \\
\hline Day & 114.93 & $<0.001$ \\
$\begin{array}{c}\text { Genotype by polymorphic marker } \\
\text { 681G }>A(r s 4244285)\end{array}$ & 10.60 & $<0.001$ \\
$\begin{array}{c}\text { Day + Genotype by polymorphic } \\
\text { marker 681G }>A(r s 4244285)\end{array}$ & 7.79 & $<0.001$ \\
\hline
\end{tabular}

The results of the two-way analysis of variance are presented in Table 3.

Statistical significance was obtained for the study day $(F=114.93, p<0.001)$ and genotype parameters $(\mathrm{F}=10.60, \mathrm{p}<0.001)$.

To investigate the safety of therapy in patients with different genotypes, the two-way analysis of variance was performed including the CYP2C19 genotype and the day of the study as covariates. The results of data analysis performed for the UKU scale in patients with different genotypes are presented in Table 4.

Table 4. The UKU scale scores in patients with different genotypes from Day 1 to Day 6 of the study.

\begin{tabular}{ccccccc}
\hline \multirow{2}{*}{ Genotypes } & \multicolumn{7}{c}{ The UKU scale scores } \\
& \multicolumn{7}{c}{ Day 1} & Day 2 & Day 3 & Day 4 & Day 5 & Day 6 \\
\cline { 2 - 6 } & $0[0 ; 0]$ & $3[3 ; 4]$ & $4[4 ; 5]$ & $6[5 ; 7]$ & $7[6 ; 8]$ & $7[6 ; 8]$ \\
GG & $0[0 ; 0]$ & $3[3 ; 3]$ & $5[4 ; 5]$ & $7[7 ; 7]$ & $10[9 ; 10]$ & $10[9 ; 10]$ \\
\hline
\end{tabular}




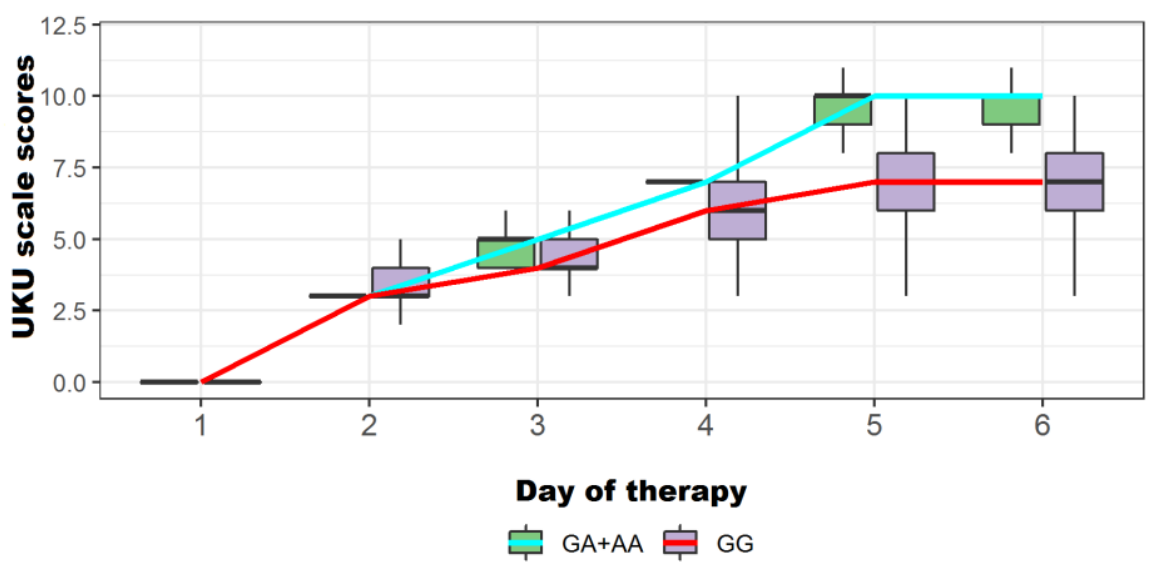

Figure 2. Dynamics of changes in the UKU scale scores across patients with different genotypes from Day 1 to Day 6 of therapy.

Table 5. Comparison of the UKU scale scores in patients with different genotypes from Day 1 to Day 6 of the study.

\begin{tabular}{cccc}
\hline Parameter & $G G$ & $G A+A A$ & p-value \\
\hline $\begin{array}{c}\text { Diazepam plasma concentration, } \\
\text { ng/ml }\end{array}$ & $199.83[82.92 ; 250.58]$ & $313,47[288,99 ; 468,33]$ & 0,040 \\
$\begin{array}{c}\text { Diazepam saliva concentration, } \\
\mathrm{ng} / \mathrm{ml}\end{array}$ & $2.80[0.73 ; 3.80]$ & $5.33[5.14 ; 6.00]$ & 0,003 \\
\hline
\end{tabular}

Dynamics of changes in the UKU scale scores across patients with different genotypes by polymorphic marker $681 G>A(r s 4244285)$ are shown in Figure 2.

The results of the two-way analysis of variance are presented in Table 5.

We revealed a statistically significant difference in plasma concentration levels of diazepam across patients with different genotypes: $(G G) 199.83$ [82.92; 250.58] vs $(G A+A A)$ 313.47 [288.99; 468.33], $\mathrm{p}=0.040$ (Figure 3).

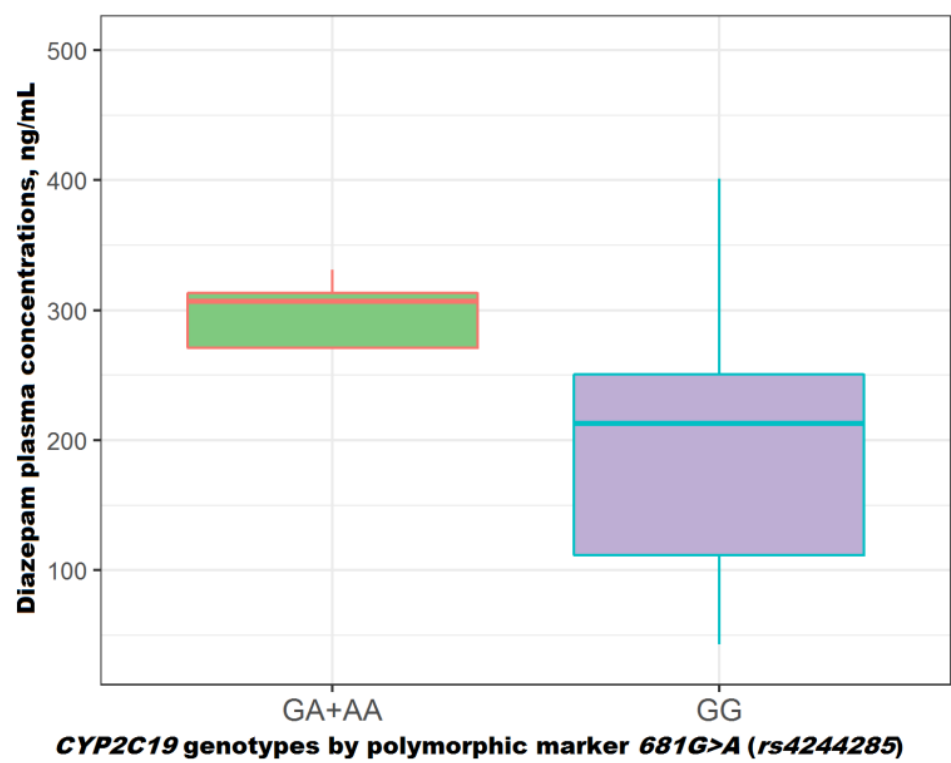

Figure 3. Differences in plasma concentration levels of diazepam in patients with different genotypes. 


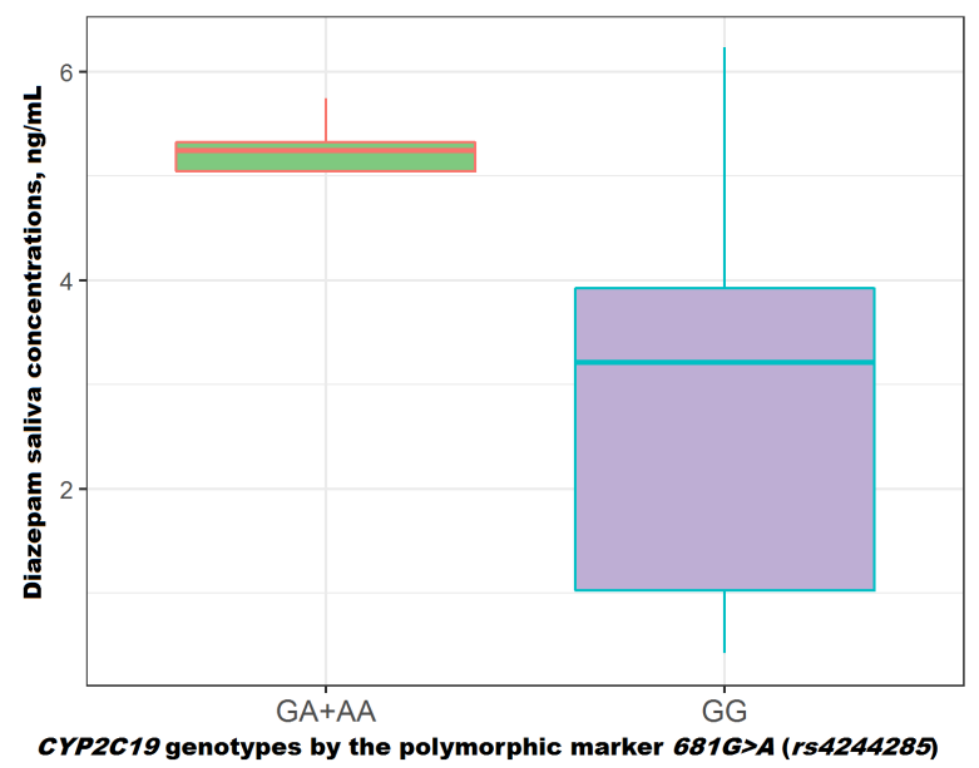

Figure 4. Differences in saliva concentration levels of diazepam in patients with different genotypes.

Pharmacokinetic study revealed that saliva concentrations of diazepam in patients with different genotypes by polymorphic marker $681 G>A$ (rs4244285) also has the statistically significant differences: $(G G) 2.80[0.73 ; 3.80]$ vs $(G A+A A) 5.33[5.14 ; 6.00], \mathrm{p}=0.003)$. A comparison of saliva concentration levels of diazepam in patients with different genotypes is presented in Figure 4.

\section{Discussion}

The results of our study revealed the difference between the efficacy and safety profiles of diazepam in patients with AWS carrying different genotypes of the CYP2C19 gene by polymorphic marker $681 G>A$ ( $r s 4244285)$.

The efficacy of diazepam therapy (as evaluated by the psychometric scales) was different across the patients with AWS carrying different genotypes: the difference in CIWAAr scores before the therapy and after it was lower in patients with the GG genotype in comparison with those who carried the $G A$ and $A A$ genotypes. This is presumably related to the decreased CYP2C19 isoenzyme activity in patients carrying the GA and $A A$ genotypes. This, in turn, leads to the reduced biotransformation rates of diazepam, an increase in concentration rates of the drug in plasma and more pronounced effect of the medication.

Patients carrying the $G A$ and $A A$ genotypes showed a higher increase in the UKU scale scores, which demonstrate that such patients have a higher risk of ADR occurrence than the GG genotype carriers do. This appears to be due to the decreased activity of the CYP2C19 isoenzyme in patients carrying the minor allele $A$ by polymorphic marker $681 G>A$ (rs4244285) of the CYP2C19 gene. The decreased activity of the CYP2C19 isoenzyme leads to the reduced biotransformation rates of diazepam, which in turn leads to an increase in plasma concentration of the drug and to an enhanced risk of undesirable side effects.

Pharmacokinetic study revealed that carriers of the wild-type genotype have a lower level of both plasma and saliva diazepam concentrations, which is probably due to the reduced diazepam biotransformation in the carriers of the minor allele $A$.

Thus, based on the study results, one would assume that patients who carry the GG genotype have a higher risk of absence of the intended therapeutic effect of diazepam, 
which leads to persistence of the anxiety, fear and emotional tension in the clinical presentation of patients. To reduce this risk, such cohort of patients requires the prescription of medications, which are not metabolized by CYP2C19, or administration of higher doses of diazepam. Furthermore, it is possible to suppose that the carriers of the minor nonmutant genotype by polymorphic marker $681 G>A$ (rs4244285) of $C$ YP2C19 gene have a higher risk of ADR occurrence during the diazepam administration.

These results are consistent with the findings of our previous study focused on investigation of the CYP2C19*2 genetic polymorphism, which had a 2-times lower sample size and enrolled 50 patients [7]. Furthermore, previous studies which were conducted by our research group $[14,15]$, confirm the importance, relevance and possibility to investigate the personalized approach to the prescription of BZDs (and specifically diazepam) in such cohort of patients.

\title{
Conclusions
}

The study conducted in 100 patients with AWS revealed the correlation between the CYP2C19*2 genetic polymorphisms and the efficacy and safety of diazepam. Furthermore, a statistically significant difference in both plasma and saliva concentration levels of diazepam across patients with different genotypes was revealed.

\begin{abstract}
Author Contributions: Conceptualization, V.Yu.S., M.S.Z., E.A.B., and D.A.S.; methodology, V.Yu.S.; software, M.S.Z.; validation, V.Yu.S. and M.S.Z.; formal analysis, V.V.S.; investigation, V.Yu.S., E.A.G., K.A.R., T.E.G.; resources, E.A.G. and K.A.R.; data curation, V.Yu.S. and M.S.Z.; writing-original draft preparation, V.Yu.S.; writing-review and editing, M.S.Z., E.A.B., and D.A.S.; visualization, V.A.S.; supervision, M.S.Z., E.A.B. and D.A.S.; project administration, V.V.S. All authors have read and agreed to the published version of the manuscript.
\end{abstract}

Funding: This research received no external funding.

Institutional Review Board Statement: The study was conducted according to the guidelines of the Declaration of Helsinki and approved by the local ethical committee of the MOSCOW RESEARCH AND PRACTICAL CENTRE ON ADDICTIONS (protocol code 07-17 from 11/28/2017).

Informed Consent Statement: Informed consent was obtained from all subjects involved in the study. RESEARCH AND PRACTICAL CENTRE ON ADDICTIONS (protocol code 07-17 from 11/28/2017).

Conflicts of Interest: The authors declare no conflict of interest.

\section{References}

1. Fukasawa, T.; Suzuki, A.; Otani, K. Effects of genetic polymorphism of cytochrome P450 enzymes on the pharmacokinetics of benzodiazepines. J Clin Pharm Ther 2007, 32, 333-41.

2. Sachdeva, A.; Choudhary, M.; Chandra, M. Alcohol Withdrawal Syndrome: Benzodiazepines and Beyond. J Clin Diagn Res 2015, 9, VE01-VE07.

3. Benedict, N.J.; Wong, A.; Cassidy, E.; Lohr, B.R.; Pizon, A.F.; Smithburger, P.L.; Falcione, B.A.; Kirisci, L.; Kane-Gill, S.L. Predictors of resistant alcohol withdrawal (RAW): A retrospective case-control study. Drug Alcohol Depend 2018, 192, $303-308$.

4. Hack, J.B.; Hoffman, R.S.; Nelson, L.S. Resistant alcohol withdrawal: does an unexpectedly large sedative requirement identify these patients early? J Med Toxicol 2006, 2, 55-60.

5. Sarff, M.; Gold, J.A. Alcohol withdrawal syndromes in the intensive care unit. Crit Care Med 2010, 38, 494-501.

6. Gold, J.A.; Rimal, B.; Nolan, A.; Nelson, L.S. A strategy of escalating doses of benzodiazepines and phenobarbital administration reduces the need for mechanical ventilation in delirium tremens. Crit Care Med 2007, 35, 724-30.

7. Skryabin, V.Y.; Zastrozhin, M.S.; Torrado, M.V.; Grishina, E.A.; Ryzhikova, K.A.; Shipitsyn, V.V.; Galaktionova, T.E.; Sorokin, A.S.; Bryun, E.A.; Sychev, D.A. How do CYP2C19*2 and CYP2C19*17 genetic polymorphisms affect the efficacy and safety of diazepam in patients with alcohol withdrawal syndrome? Drug Metab Pers Ther 2020, 35, 1-8.

8. Fukasawa, T.; Yasui-Furukori, N.; Suzuki, A.; Inoue, Y.; Tateishi, T.; Otani, K. Pharmacokinetics and pharmacodynamics of etizolam are influenced by polymorphic CYP2C19 activity. Eur J Clin Pharmacol 2005, 61, 791-5. 
9. Lepper, E.R.; Baker, S.D.; Permenter, M.; Ries, N.; van Schaik, R.H.; Schenk, P.W.; Price, D.K.; Ahn, D.; Smith, N.F.; Cusatis, G.; Ingersoll, R.G.; Bates, S.E.; Mathijssen, R.H.; Verweij, J.; Figg, W.D.; Sparreboom, A. Effect of common CYP3A4 and CYP3A5 variants on the pharmacokinetics of the cytochrome P450 3A phenotyping probe midazolam in cancer patients. Clin Cancer Res 2005, 11, 7398-404.

10. Jose, M.; Mathaiyan, J.; Kattimani, S.; Adithan, S.; Chandrasekaran, A. Role of CYP2C19 gene polymorphism in acute alcohol withdrawal treatment with loading dose of diazepam in a South Indian population. Eur J Clin Pharmacol 2016, 72, 807-12.

11. Kranzler, H.R.; Edenberg, H.J. Pharmacogenetics of alcohol and alcohol dependence treatment. Curr Pharm Des 2010, 16, 21418.

12. Nuss, M.A.; Elnicki, D.M.; Dunsworth, T.S.; Makela, E.H. Utilizing CIWA-Ar to assess use of benzodiazepines in patients vulnerable to alcohol withdrawal syndrome. WV Med J 2004, 100, 21-5.

13. Lingjaerde, O.; Ahlfors, U.G.; Bech, P.; Dencker, S.J.; Elgen, K. The UKU side effect rating scale. A new comprehensive rating scale for psychotropic drugs and a cross-sectional study of side effects in neuroleptic-treated patients. Acta Psychiatr Scand Suppl 1987, 334, 1-100.

14. Zastrozhin, M.S.; Savchenko, L.M.; Bryun, E.A.; Skryabin, V.Y.; Grishina, E.A.; Denisenko, N.P.; Markov, D.D.; Sychev, D.A. Effects of CYP2D6 genetic polymorphisms on the efficacy and safety of fluvoxamine in patients with depressive disorder and comorbid alcohol use disorder. Pharmgenomics Pers Med 2018, 11, 113-119.

15. Skryabin, V.Y.; Zastrozhin, M.S.; Torrado, M.V.; Grishina, E.A.; Ryzhikova, K.A.; Shipitsyn, V.V.; Galaktionova, T.E.; Sorokin, A.S.; Bryun, E.A.; Sychev, D.A. Effects of CYP2C19*17 Genetic Polymorphisms on the Steady-State Concentration of Diazepam in Patients With Alcohol Withdrawal Syndrome. Hospital Pharmacy 2020, 1-5. 